\title{
Interactive comment on "Modelling Silicate - Nitrate - Ammonium co-limitation of algal growth and the importance of bacterial remineralisation based on an experimental Arctic coastal spring bloom culture study" by Tobias R. Vonnahme et al.
}

Anonymous Referee \#3

Received and published: 11 November 2020

In the manuscript "Modelling Silicate - Nitrate - Ammonium co-limitation of algal growth and the importance of bacterial remineralisation based on an experimental Arctic coastal spring bloom culture study" by Vonnahme et al. the authors present a new model development for diatom co-limitation of nutrients. Based on experimental data they expand the classical model by Geider et al. (1998), which remains its feasibility for larger (ecosystem) models, while improving the representation of algae growth. Improving biological parameterizations in ecosystem models is important and contributes Discussion paper to to improving their predicative capability. However, the authors should address a 
some points listed below.

The authors report that "With the onset of the stationary phase in the bacteria-enriched cultures about $30 \%$ of the cells formed biofilms on the walls of the cultivation bottles (estimated after sonication treatment)." (line 230). The formation of such biofilms has occurred in other experiments before and cannot always be avoided. However, it does potentially have a huge impact of microbial dynamics and interactions. Therefore only reporting (and discussing) it is in sufficient, if one is to compare experimental results with a new modelling approach. I would suggest to run a model sensitivity analysis specifically targeting this.

The authors appropriately discuss quota models and their use. A different approach to model celluar nutrient kinetics, that has been argued to be more mechanistic, considers uptake sites for nutrients (Aksnes \& Egge, 1991, Mar Ecol Prog Ser. 70:65-72). A good, though slightly technical, paper applying this approach and combining it with variable cellular stoichiometry is Flynn et al., 2018, PLoS Comput Biol 14(4): e1006118. Setting up a model like this for your data could be highly interesting, but beyond the scope of this study. However discussion the approach would provide a very useful context.

In the introduction (line 46) and in the discussion the authors mention the role of the impact of climate change on coastal phytoplankton succession, including projected increased DOM inputs via river run off. Several studies have found and/or suggested a delayed bloom due to increase turbidity (e.g. Opdal et al. 2019, Glob Change Biol. 2019;00:1-8), which should be mentioned here.

The authors mention both nitrate and ammonium as nitrogen sources. Additionally, urea can be a relevant nitrogen source in some systems. I am not sure how much of a role this plays in arctic ecosystems, but it should either be discussed or mentioned why it does not play a significant role.

Line 168: ". . .but the growth rate can be reduced (Hildebrand, 2002; Gilpin, 2004)". How can the growth rate be reduced? What can lead to this reduction?

Printer-friendly version

Discussion paper 
Figure 6 and figure 7 do not exist.

Line 660: Table 1 is not the most up-to-date. Especially on the ecosystem model side it would be nice to see more recent developments reflected as well.

Especially in the abstract and the introduction there are several long (sometimes convoluted) sentences. To increase readability it would be could to rephrase these (Schachtelsaetze sind im Englischen nicht so hoch angesehen wie im Deutschen ;)).

Interactive comment on Biogeosciences Discuss., https://doi.org/10.5194/bg-2020-314, 2020. 